\title{
miR-874 regulates myocardial necrosis by targeting caspase-8
}

\author{
K Wang ${ }^{1}$, F Liu ${ }^{1}$, L-Y Zhou ${ }^{1}$, S-L Ding ${ }^{1}$, B Long ${ }^{1}$, C-Y Liu ${ }^{1}$, T Sun ${ }^{1}$, Y-Y Fan ${ }^{1}$, L Sun ${ }^{2}$ and P-F Li, ${ }^{* 1,3}$
}

Cardiomyocyte death is an important reason for the cardiac syndromes, such as heart failure (HF) and myocardial infarction (MI). In the heart diseases, necrosis is one of the main forms of cell death. MicroRNAs (miRNAs) are a class of small non-coding RNAs that mediate post-transcriptional gene silencing. Hitherto, it is not yet clear whether miRNA can regulate necrosis in cardiomyocyte. In this work, we performed a microarray to detect miRNAs in response to $\mathrm{H}_{2} \mathrm{O}_{2}$ treatment, and the results showed that miR-874 was substantially increased. We further studied the function of miR-874, and observed that knockdown of miR-874 attenuated necrosis in the cellular model and also MI in the animal model. We searched for the downstream mediator of miR-874 and identified that caspase-8 was a target of miR-874. Caspase-8 was able to antagonize necrosis. When suppressed by miR-874, caspase-8 lost the ability to repress necrotic program. In exploring the molecular mechanism by which miR-874 expression is regulated, we identified that Foxo3a could transcriptionally repress miR-874 expression. Foxo3a transgenic or knockout mice exhibited a low or high expression level of miR-874, and a reduced or enhanced necrosis and MI. Our present study reveals a novel myocardial necrotic regulating model, which is composed of Foxo3a, miR-874 and caspase-8. Modulation of their levels may provide a new approach for tackling myocardial necrosis.

Cell Death and Disease (2013) 4, e709; doi:10.1038/cddis.2013.233; published online 4 July 2013

Subject Category: Experimental Medicine

MicroRNAs (miRNAs) are a class of small non-coding RNAs and act as negative regulators of gene expression by inhibiting mRNA translation or promoting mRNA degradation. ${ }^{1,2}$ Growing evidences have demonstrated that miRNAs can have a significant role in the regulation of development, differentiation, proliferation and apoptosis. MiRNAs can regulate cardiac function such as the conductance of electrical signals, heart muscle contraction, heart growth and morphogenesis. They also participate in the regulation of

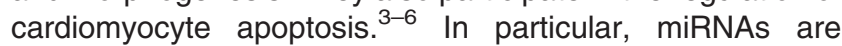
involved in the pathogenesis of cardiac diseases such as myocardial infarction (MI) and heart failure (HF), and manipulation of miRNAs can be developed to therapeutic approaches. ${ }^{7-9}$ However, it is not yet clear whether miRNAs are involved in the regulation of necrosis.

Necrosis is a type of cell death, which is morphologically characterized by increasing of cell volume, dilation of organelles, rupture of the plasma membrane and subsequent loss of intracellular contents. ${ }^{10}$ For a long time, apoptosis is considered the sole form of programmed cell death during development, homeostasis and disease, while necrosis is regarded as a passive and unregulated process. However, recent researches work suggested that necrosis was programmed in terms of both its course and its occurrence, and a proportion of necrosis was happened in a tightly regulated manner through different pathways. Necrotic cell death has been involved in regulating disease pathologies in animal models of hypoxic/ischemic injury, ${ }^{11}$ septic shock, ${ }^{12}$ acute pancreatitis ${ }^{13}$ and ischemic brain injury. ${ }^{11}$ In this sense, the study of the biochemical and molecular mechanisms of programmed necrosis could shed new light into the clinical implications.

Cardiomyocyte death is an important reason for the cardiac syndromes, such as $\mathrm{HF}, \mathrm{Ml}$ and stroke. ${ }^{14}$ Necrosis is one of the main forms of cell death and its role has been studied in the heart diseases. Guerra et al. ${ }^{15}$ first reported that the level of necrosis was greater than apoptosis in HF patients. Recent works have demonstrated that necrosis can slow down and reduce cell injury in models of cardiac infarction. ${ }^{16}$ These studies show that necrosis have an important role in the pathological process in cardiac diseases. However, the molecular components regulating programmed necrosis in heart remain largely unidentified.

Caspase- 8 is a cysteine protease that is critically involved in regulating cellular apoptosis, and has recently been shown to be important in regulating necrotic cell death. The receptor-

\footnotetext{
${ }^{1}$ Division of Cardiovascular Research, State Key Laboratory of Biomembrane and Membrane Biotechnology, Institute of Zoology, Chinese Academy of Sciences, Beijing, China; ${ }^{2}$ Center for Biological Imaging Institute of Biophysics, Chinese Academy of Sciences, Beijing, China and ${ }^{3}$ College of Medicine, University of Illinois at Chicago, Chicago, IL, USA

*Corresponding author: P-F Li, Division of Cardiovascular Research, State Key Laboratory of Biomembrane and Membrane Biotechnology, Institute of Zoology, Chinese Academy of Sciences, Beijing 100101, China. Tel: + 8610 64807098; Fax: + 8610 64807176; E-mail: lipeifeng @ ioz.ac.cn

Keywords: myocardial necrosis; miR-874; caspase-8

Abbreviations: miRNAs, microRNAs; $\mathrm{H}_{2} \mathrm{O}_{2}$, hydrogen peroxide; Foxo3a, forkhead box-containing protein, $\mathrm{O}$ subfamily $3 a$; $l / R$, ischemia/reperfusion; TNF- $\alpha$, tumor necrosis factor-alpha; PI, propidium iodide; caspase 8 , cysteine-aspartic acid protease 8 ; caspase $8^{\mathrm{C} 360 \mathrm{~S}}$, cysteine-aspartic acid protease 8 (cysteine to serine catalytically inactive mutant at amino acid 360); qRT, quantitative reverse transcription polymerase chain reaction; RIPK3, receptor-interacting serine/threonine-protein kinase 3; RIPK1, receptor-interacting serine/threonine-protein kinase 1; TP, target protector

Received 12.4.13; revised 29.5.13; accepted 29.5.13; Edited by A Stephanou
} 
interacting serine-threonine kinase 3 (RIP3) is a key signaling molecule in the programmed necrosis pathway. This pathway has important roles in a variety of physiological and pathological conditions, including development, tissue damage response and antiviral immunity. Caspase- 8 has been demonstrated to be able to cleave and inactivate RIP3, and prevent the pathway of necrosis. ${ }^{17,18}$ However, it is not yet clear whether caspase- 8 is a target of miRNAs and the molecular regulation of caspase-8 in the necrotic machinery remains to be elucidated. Addressing these questions will likely be the key to decipher the molecular pathway of necrosis.

The forkhead family of transcription factors consists of $>80$ members and divided into 19 subgroups (from $A$ to $S$ ). They are characterized by the presence of a conserved 100 aminoacid DNA-binding domain. Foxo3a is expressed in the heart and skeletal muscle ${ }^{19-21}$ and participates in regulating diverse cellular functions such as cell cycle arrest, oxidative scavenging, differentiation, metabolism, proliferation, apoptosis and survival. ${ }^{17,18}$ However, it is currently unknown whether Foxo3a can also regulate oxidative stress-induced necrosis.

Our present work aims at finding out whether miRNAs are able to regulate myocardial necrosis. In the miRNA microarray, miR-874 was identified to be upregulated by $\mathrm{H}_{2} \mathrm{O}_{2}$ stimulation. In addition, we found that caspase- 8 could be regulated by miR-874. MiR-874 affected myocardial necrosis through targeting caspase-8. In exploring the mechanism by which how miR-874 expression is regulated, we identified that Foxo3a could transcriptionally repress miR-874 expression. Foxo3a regulated caspase-8 expression and the consequent myocardial necrosis through targeting miR-874. Our results reveal a novel myocardial necrotic regulating model which is composed of Foxo3a, miR-874, caspase-8. Our results provide new insights for understanding the pathogenesis of myocardial necrosis. A better understanding of the molecular pathway may allow for the development of novel therapies to treat heart syndromes.

\section{Results}

miR-874 is involved in $\mathrm{H}_{2} \mathrm{O}_{2}$-induced necrotic cell death in cardiomyocytes. Hydrogen peroxide $\left(\mathrm{H}_{2} \mathrm{O}_{2}\right)$ is well known to be important factor inducing cell death. However, the form of cell death induced by $\mathrm{H}_{2} \mathrm{O}_{2}$ varies from apoptosis to necrosis, depending on the exact concentration applied and the cell type tested. ${ }^{22-24}$ We tested the effect of $\mathrm{H}_{2} \mathrm{O}_{2}$ in cardiomyocytes cell death, and observed that treatment with $0.2 \mathrm{mM}$ only trigged apoptosis (Figure 1a), while the concentration of $0.5 \mathrm{mM}$ preferentially caused necrosis (Figure 1b). To understand whether miRNAs are involved in the necrotic pathway induced by $\mathrm{H}_{2} \mathrm{O}_{2}$, we performed a microarray to detect miRNAs in response to $\mathrm{H}_{2} \mathrm{O}_{2}$ treatment (Figure 1c and Supplementary Table). To confirm the microarray result, we carried out quantitative reverse transcription-polymerase chain reaction (qRT-PCR) to verify miRNAs levels. Among several miRNAs, miR-874 was substantially upregulated (Figure 1d) and $\mathrm{H}_{2} \mathrm{O}_{2}$ treatment led to a time-dependent increase in miR-874 level (Figure 1e). Tumor necrosis factor-alpha (TNF- $\alpha$ ) was known as necrosis inducer, so we also detected these miRNAs levels upon TNF- $\alpha$ stimulation. The results were similar to those induced by $\mathrm{H}_{2} \mathrm{O}_{2}$ (Supplementary Figure 1).

Next, we attempted to understand the function of miR-874 in necrotic machinery. Necrosis is morphologically characterized by increasing of cell volume, dilation of organelles, rupture of the plasma membrane and subsequent loss of intracellular contents. Cardiomyocytes upon exposure to $\mathrm{H}_{2} \mathrm{O}_{2}$ displayed obvious necrotic morphological characterization such as dilation of organelles, rupture of the plasma membrane and loss of cell integrity. However, knockdown of miR-874 by antagomir (anta-874) but not antagomir negative control (anta-NC) group attenuated the necrotic morphological hallmarks, which were confirmed by electron microscopy (Figure 1f). The antagomir of miR-874 also attenuated necrotic cell death induced by $\mathrm{H}_{2} \mathrm{O}_{2}$ (Figure 1g). These data suggest that miR-874 is involved in $\mathrm{H}_{2} \mathrm{O}_{2}$-induced necrotic cell death and has a function role in caridomyocytes.

miR-874 regulates necrotic cell death in the heart. To understand the pathophysiological role of miR-874, we detected whether miR-874 was involved in the pathogenesis of $\mathrm{MI}$ in the animal model. MiR-874 was elevated in response to ischemia/reperfusion (I/R) injury (Figure 2a). Myosin antibody injection technique was used to assess myocardial necrosis. I/R caused a massive increase in necrotic myosinpositive cells (Figures $2 b$ and $c$ ). Knockdown of miR-874 (anta-874) showed a decrease in necrotic myosin-positive cells, compared with anta-NC group upon I/R (Figures $2 \mathrm{~b}$ and c). Thus, it indicates that knockdown of miR-874 results in a reduction in the myocardial necrosis. The myocardial infarct sizes were also reduced in anta-874 group (Figure 2d) and the cardiac function was ameliorated by knockdown of miR-874 (Figure 2e). Thus, miR-874 may have a significant role in myocardial necrosis and $\mathrm{MI}$.

miR-874 participates in the regulation of caspase-8 expression. The importance of caspase- 8 has been demonstrated by many works in the apoptosis, and has recently been reported in the necrosis. ${ }^{25,26}$ To find out the executioner of miR-874 in necrotic cascades, we analyzed its potential targets using bioinformatics program of RNAhybrid. We observed that caspase- 8 was a potential target of miR874 (Figure 3a). Then we tested whether miR-874 could influence the endogenous caspase-8 expression. Enforced expression of miR-874 induced a reduction of endogenous caspase-8 expression (Figure $3 \mathrm{~b}$ ). To understand whether the effect of miR-874 on caspase- 8 is specific, we employed the target protector technology. The inhibitory effect of miR874 on caspase-8 expression was reduced in the presence of the target protector (Figure $3 \mathrm{c}$ ). These results indicate that miR-874 can specifically regulate caspase-8.

We employed the luciferase assay system to test whether miR-874 can influence the translation of caspase-8. As shown in Figure $3 e$, the luciferase reporter assay revealed that miR874 could reduce the translation of caspase-8. Introduction of mutations, which disrupt base pairing between miR-874 and caspase-8 (Figure 3d), rescued luciferase expression (Figure $3 e$ ) and caspase-8 protein expression (Figures $3 f$ 
a

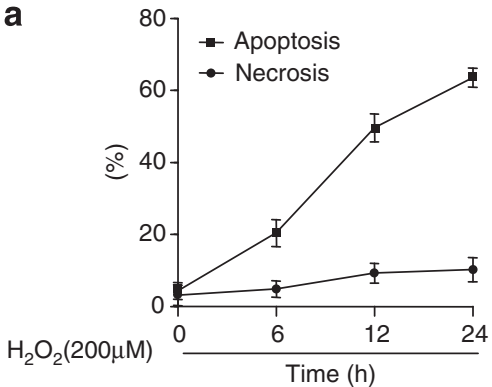

C

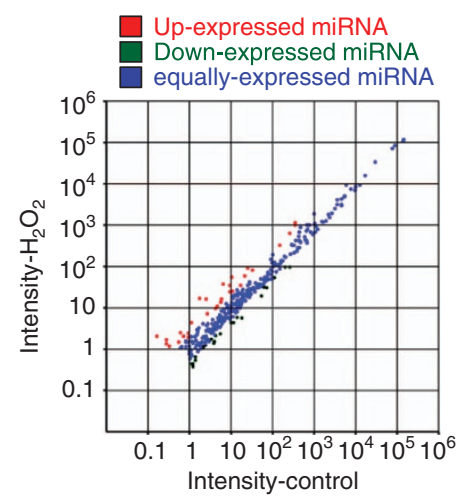

b

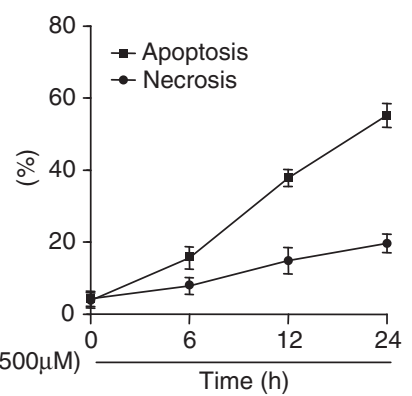

d

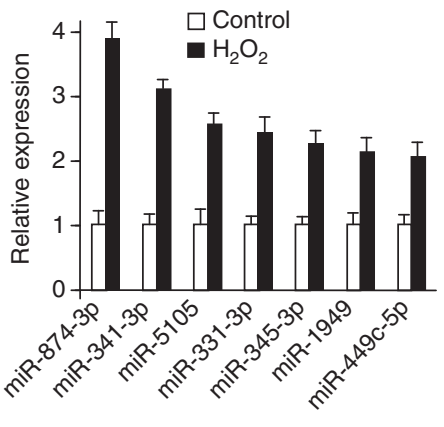

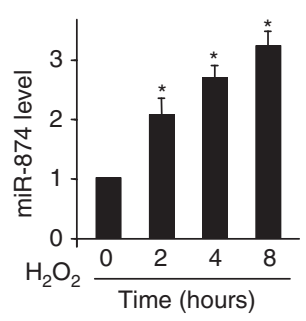

f Control

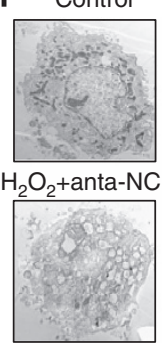

$\mathrm{H}_{2} \mathrm{O}_{2}$

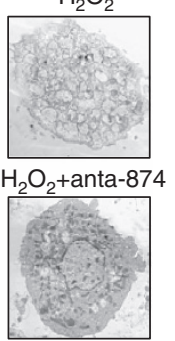

g

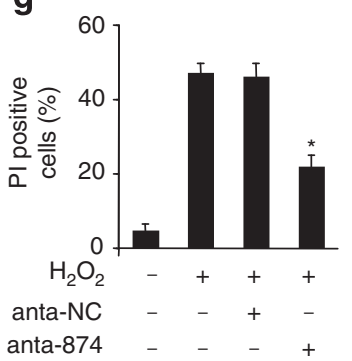

Figure 1 miRNAs are involved in $\mathrm{H}_{2} \mathrm{O}_{2}$-induced necrotic cell death in caridomyocytes. (a and $\mathbf{b}$ ) $\mathrm{H}_{2} \mathrm{O}_{2}$ induces apoptosis and necrosis in cardiomyocytes. Cardiomyocytes were treated with $200 \mu \mathrm{M} \mathrm{H}_{2} \mathrm{O}_{2}$ (a) or $500 \mu \mathrm{M} \mathrm{H}_{2} \mathrm{O}_{2}$ (b) at indicated time. Apoptotic cells were analyzed by flow cytometry analysis of the active caspase-3 using the Vybrant FAM caspase-3 assay. Necrotic cell death was assessed by flow cytometry using a PI exclusion assay. (c) Microarray results depicting the log-log scatter plot of intensity of miRNA expression from control versus $\mathrm{H}_{2} \mathrm{O}_{2}$ treatment. Cardiomyocytes were untreated (control) or treated with $500 \mu \mathrm{M} \mathrm{H}_{2} \mathrm{O}_{2}$. miRNAs were detected by microarray. The red dots and the green dots indicate twofold up- or downregulated genes, respectively. (d) Upregulated miRNAs upon $\mathrm{H}_{2} \mathrm{O}_{2}$ treatment. Cardiomyocytes were treated with $\mathrm{H}_{2} \mathrm{O}_{2}$ for $24 \mathrm{~h}$, and the expression of miRNAs was analyzed. (e) qRT-PCR analysis of miR-874. Cardiomyocytes were treated with $\mathrm{H}_{2} \mathrm{O}_{2}$ at the indicated time, and the expression of miR-874 was analyzed, ${ }^{*} P<0.05$ versus control. (f and g) Knockdown of miR-874 reduces necrotic responses induced by $\mathrm{H}_{2} \mathrm{O}_{2}$. Cardiomyocytes were transfected with miR874 antagomir (anta-874) or antagomir control (anta-NC). Twenty-four hours after transfection, cells were treated with $\mathrm{H}_{2} \mathrm{O}_{2}$. Necrosis was assessed by EM (F) and $\mathrm{PI}$ exclusion $(\mathrm{G})$, ${ }^{\star} P<0.05$ versus $\mathrm{H}_{2} \mathrm{O}_{2}$ alone

and g). Taken together, it appears that caspase- 8 is a specific target of miR-874.

miR-874 regulates necrosis through targeting caspase-8. Caspase-8 has recently been shown to be able to regulate intestinal homeostasis from TNF- $\alpha$-induced necrotic cell death. ${ }^{27}$ We tested whether caspase- 8 was related to the occurrence of necrosis induced by $\mathrm{H}_{2} \mathrm{O}_{2}$ or I/R in cardiomyocytes. Enforced expression of caspase-8 attenuated necrotic cell death (Figure 4a) induced by $\mathrm{H}_{2} \mathrm{O}_{2}$. However, overexpression of the caspase-8 ${ }^{\text {C360S }}$ (cysteine to serine mutation at the catalytically active site) lost this protective effects. It suggests that the suppression of necrotic cell death by caspase-8 requires its catalytic activity.
To understand the role of caspase- 8 in myocardial necrosis in the animal model, we employed I/R model. Enforced expression of caspase-8 resulted in a reduction in myocyte necrosis (Figure $4 b$ ) upon I/R. These data suggest that caspase- 8 can inhibit necrosis induced by $\mathrm{H}_{2} \mathrm{O}_{2}$ or I/R injury.

To figure out how miR-874 elicits its effect on necrotic program, we tested whether caspase- 8 was a downstream target of miR-874. Caspase-8-siRNA was constructed. The antagomir of miR-874 inhibited $\mathrm{H}_{2} \mathrm{O}_{2}$-induced necrosis, however, this effect was attenuated by knockdown of caspase-8 (Figures $4 \mathrm{c}$ and $\mathrm{d}$ ). The target protector of caspase- 8 could inhibit necrosis induced by $\mathrm{H}_{2} \mathrm{O}_{2}$ (Figures $4 \mathrm{e}$ and f). RIPK1 and RIPK3 are two key signaling molecules in the programmed necrosis pathway, the enzymatic activity of 


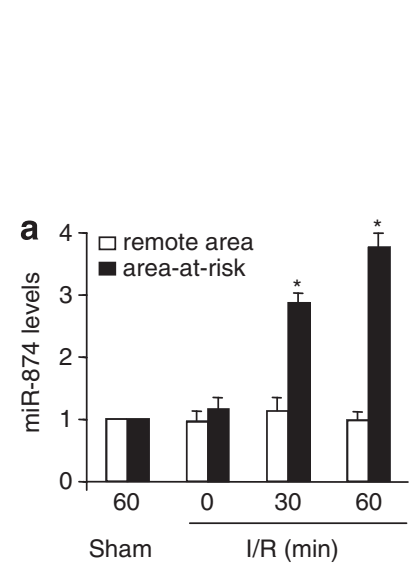

b

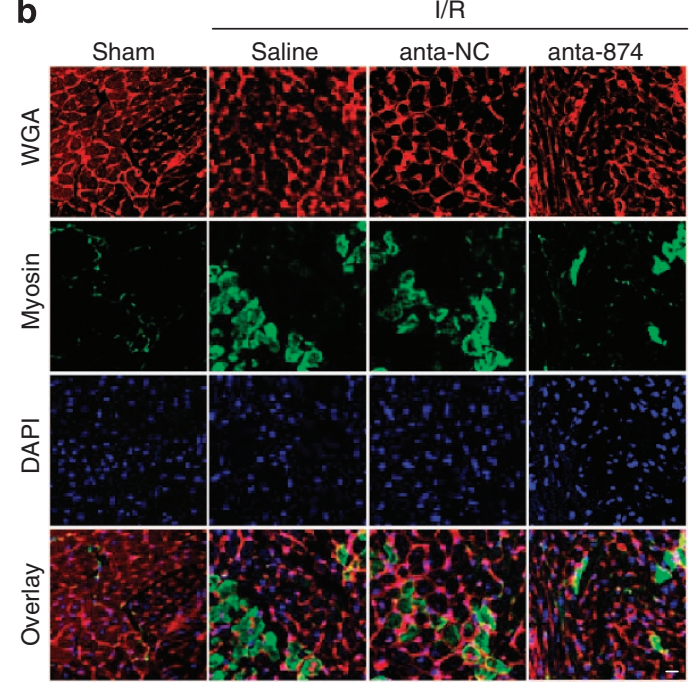

C $\square$ WT+Sham $\square$ anta-NC+l/R
$\square$ Saline+l/R $\square$ anta-874+l/R

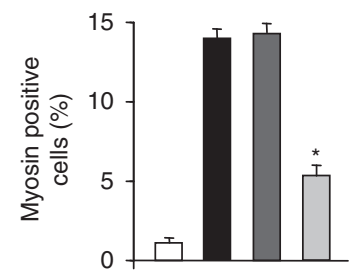

d $\square \mathrm{WT}+$ Sham $\square$ anta-NC+l/R

- Saline+l/R $\square$ anta-874+l/R

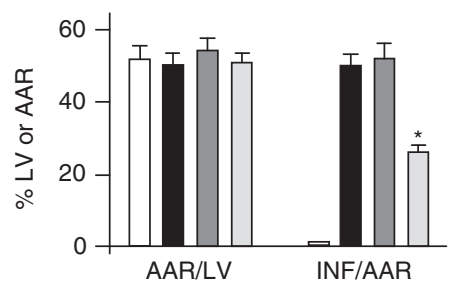

e
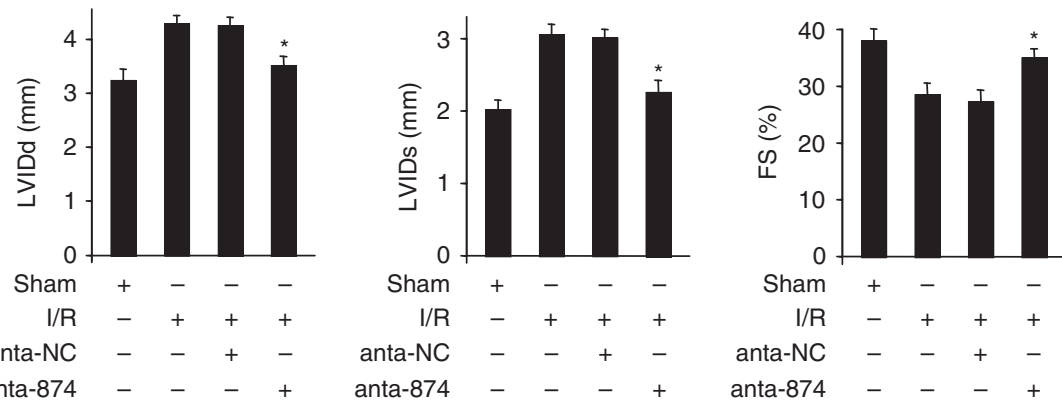

Figure 2 miR-874 is able to regulate necrosis in the heart. (a) miR-874 levels during myocardial I/R. Mice were induced to undergo cardiac I/R. Area at risk and the remote area were prepared at the indicated time for qRT-PCR analysis of miR-874 levels, $n=6,{ }^{*} P<0.05$ versus 0 min or sham. (b and $\mathbf{c}$ ) Knockdown of miR-874 attenuates myocardial necrosis upon I/R. Mice were subjected to I/R as described in methods. $\mathbf{b}$ : Immunohistochemistry for myosin antibody incorporation into the heart (green); red is a wheat germ stain for cell membranes; nuclei are shown in blue. Percentage of cells with myosin antibody infiltration was shown $(\mathbf{c}), n=6,{ }^{*} P<0.05$ versus $\mathrm{l} / \mathrm{R}$ alone. (d) Knockdown of miR-874 inhibits Ml. Mice were treated as described in b. Infarct sizes were shown, $n=6,{ }^{*} P<0.05$ versus l/R + NC. (e) Knockdown of miR-874 preserves cardiac function upon I/R. Transthoracic echocardiographic analysis was performed after $60 \mathrm{~min}$ ischemia followed by 1 week reperfusion. Diastolic left ventricular internal diameters (LVIDd); Systolic left ventricular internal diameters (LVIDs); fractional shortening of left ventricular diameter (FS), ${ }^{*} P<0.05$ versus I/R alone

which are important in the execution of necrosis. Caspase-8 has been demonstrated to be able to cleave and inactivate both RIPK1 and RIPK3, and prevent the pathway of necrosis. ${ }^{17,18}$ Here, we tested whether RIPK1 and RIPK3 could be involved in $\mathrm{H}_{2} \mathrm{O}_{2}$.induced cardiomyocytes necrosis. Our results showed that RIPK1 and RIPK3 levels were elevated in response to $\mathrm{H}_{2} \mathrm{O}_{2}$ treatment (Supplementary Figures 2A and 2C). Knockdown of RIPK1 and RIPK3 both attenuated necrotic cell death induced by $\mathrm{H}_{2} \mathrm{O}_{2}$ (Supplementary Figures $2 \mathrm{~B}$ and $2 \mathrm{D}$ ). These data suggest that miR-874 and caspase-8 are functionally linked and miR-874 exerts its effect through caspase-8.
miR-874 is a transcriptional target of Foxo3a. We asked why miR-874 is upregulated in response to the pathological insults. Our previous work has shown that the expression of a miRNA can be regulated at the transcriptional level. We analyzed the promoter region of mouse miR-874 and observed that there are two potential-binding sites of Foxo3a (Figure 5a). We tested whether Foxo3a could bind to the promoter region of miR-874. Chromatin immunoprecipitation (ChIP) assay revealed a decrease in the association levels of Foxo3a with binding site 2 (BS2) in response to $\mathrm{H}_{2} \mathrm{O}_{2}$ treatment. However, an association of Foxo3a with BS1 was not detectable (Figure 5b). Next, we tested whether Foxo3a 
a

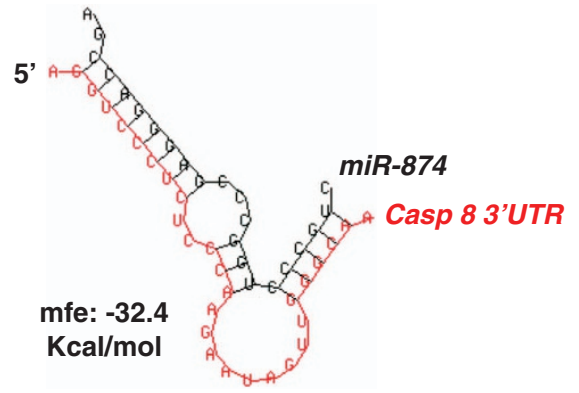

b

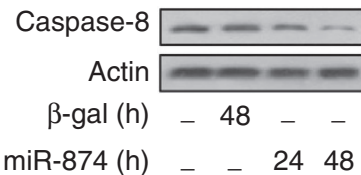

miR-874 (h) _ $\quad 2448$
C

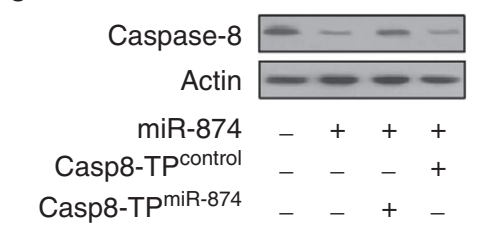

d

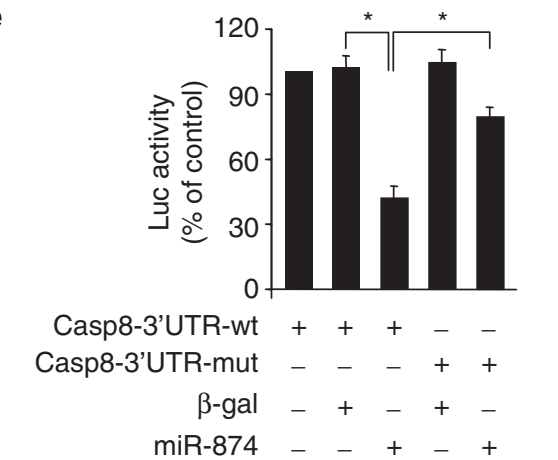

f

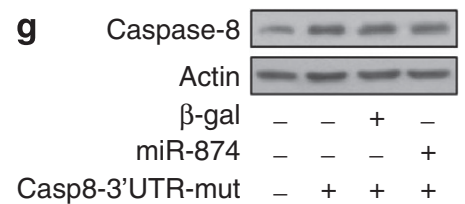

Figure 3 miR-874 participates in the regulation of caspase-8 expression. (a) Putative miR-874 sites in the $3^{\prime} U T R$ region of caspase-8. This putative miR-874 sites in the caspase-8 3 'UTR region were analyzed by RNAhybrid program. (b) miR-874 suppresses the expression of caspase-8 in the cellular model. Cardiomyocytes were infected with adenoviral miR-874 or $\beta$-gal. Caspase-8 expression was analyzed by immunoblot. (c) Caspase-8 target protector attenuates caspase-8 reduction induced by miR-874. Cardiomyocytes were infected with adenoviral miR-874, and then transfected with the target protector (caspase-8-TP ${ }^{\mathrm{miR}-874}$ ) or the control (caspase-8-TP ${ }^{\text {control }}$ ). Forty-eight hours after transfection, caspase-8 was analyzed by immunoblot. (d) Caspase-8 wild-type (WT) $3^{\prime}$ UTR and a mutated $3^{\prime}$ UTR in the miR-874-binding site are shown. (e) Luciferase assay. HEK293 cells were infected with adenoviral miR-874 or $\beta$-gal, then transfected with the luciferase constructs of the wild-type caspase-8-3'UTR (casp8$3^{\prime}$ UTR-WT) or a mutated caspase-8-3'UTR (casp8-3'UTR-mut). The luciferase activity was analyzed, ${ }^{*} P<0.05$. ( $\mathrm{f}$ and $\mathbf{g}$ ) miR-874 can suppress the expression of caspase-8 with wild-type but not mutated UTR. Cardiomyocytes were coinfected with the adenoviral miR-874 or $\beta$-gal, along with caspase-8 with wild-type UTR (casp8-3'UTR-WT) or the mutated UTR (casp 8-3'UTR-mut). Caspase-8 levels were detected by immunoblot

could influence miR-874 promoter activity. Wild-type miR874 promoter (WT) demonstrated a low activity in the presence of Foxo3a. However, mutations in the Foxo3a consensus-BS2 could abolish the inhibitory effect of Foxo3a on miR-874 promoter activity (Figure 5c). These data suggest that $\mathrm{BS} 2$ is the actual Foxo3a-binding site. $\mathrm{H}_{2} \mathrm{O}_{2}$ could induce a increase in miR-874 promoter activity (Figure 5d).Concomitantly, enforced expression of Foxo3a could attenuate the increase of miR-874 promoter activity induced by $\mathrm{H}_{2} \mathrm{O}_{2}$ in cardiomyocyte (Figure $5 \mathrm{~d}$ ). Enforced expression of Foxo3a led to a decrease of miR-874 levels (Figure 5e). Foxo3a transgenic mice demonstrated a low level of miR-874 (Figure 5f), whereas Foxo3a knockout mice exhibited an increased expression level of miR-874 (Figure $5 \mathrm{~g}$ ). These data indicate that miR-874 can be transcriptionally repressed by Foxo3a.

Foxo3a inhibits necrosis through miR-874 and caspase-8. We tested the role of Foxo3a in necrosis.
$\mathrm{H}_{2} \mathrm{O}_{2}$ induced a reduction in Foxo3a expression level (Figure $6 \mathrm{a}$ ). $\mathrm{H}_{2} \mathrm{O}_{2}$-induced the elevation of miR-874 level (Figure 6b) and necrotic cell death were attenuated by Foxo3a (Figures $6 \mathrm{~b}$ and $\mathrm{c}$ ). Foxo3a transgenic mice inhibited the elevation of miR-874 level upon I/R (Figure $6 \mathrm{~d}$ ). Foxo3a transgenic mice exhibited elevated level of caspase-8 upon I/R (Figure 6e). Furthermore, Foxo3a transgenc mice showed less myosin antibody incorporation than WT group upon I/R, which indicated a reduction in myocardial necrosis (Figure 6f). Ml sizes in Foxo3a transgenic mice also showed a remarkable decrease, compared with WT group upon I/R (Figure 6g). On the contrary, Foxo3a knockout mice showed a lower level of caspase 8 than WT group (Supplementary Figure $3 \mathrm{~A}$ ) and, therefore, more prone to I/R injury (Supplementary Figure 3B). The CYLD processing is necessary for caspase-8 mediated inhibition of necrosis. ${ }^{28}$ So, we also detected the degradation of CYLD, and the results showed that the cleavage of CYLD was lower in Foxo3a KO mice than WT group upon I/R injury 
a

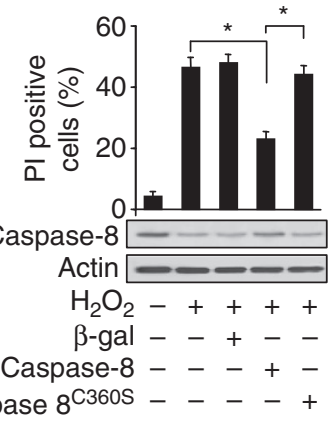

c

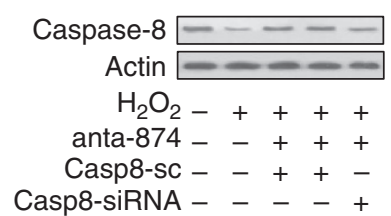

e

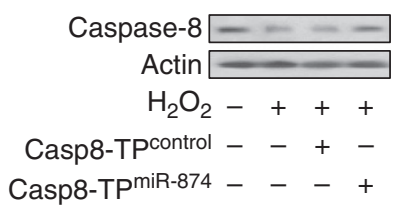

b

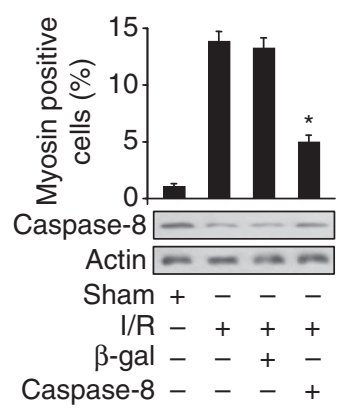

d

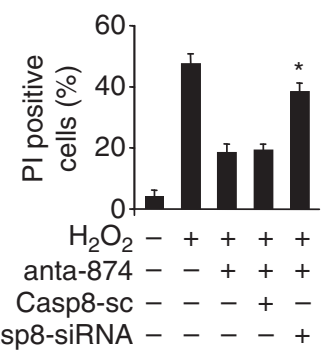

f

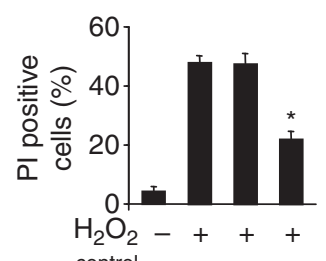

Casp8-TPcontrol --+-

Casp8-TPmiR-874 - $-\quad+$

Figure 4 miR-874 regulates necrosis through targeting caspase-8. (a) Enforced expression of caspase-8 reduces necrotic cell death induced by $\mathrm{H}_{2} \mathrm{O}_{2}$. Cardiomyocytes were infected with adenoviral caspase-8, caspase- $8{ }^{\mathrm{C} 360 \mathrm{~S}}$ (cysteine to serine mutation at the catalytically active site) or $\beta$-gal. Twenty-four hours after infection, cells were treated with $\mathrm{H}_{2} \mathrm{O}_{2}$. Necrotic cell death was assessed by flow cytometry using a PI exclusion assay, ${ }^{*} P<0.05$. (b) Enforced expression of caspase-8 attenuates myocardial necrosis upon I/R. Mice were treated as described in methods. Percentage of cells with myosin antibody infiltration was shown, $n=6,{ }^{*} P<0.05$ versus I/R alone. (c and d) Knockdown of caspase-8 can attenuate the inhibitory effect of miR-874 antagomir on $\mathrm{H}_{2} \mathrm{O}_{2}$-induced caspase-8 expression and necrosis. Cardiomyocytes were infected with adenoviral caspase-8-siRNA (casp8-siRNA) or its scramble form (casp8-sc), transfected with miR874 antagomir (anta-874) and exposed to $\mathrm{H}_{2} \mathrm{O}_{2}$. Cells were harvested at $48 \mathrm{~h}$ after treatment for the analysis of caspase-8 levels (c) and $\mathrm{PI}$ exclusion (d), ${ }^{*} P<0.05$ versus $\mathrm{H}_{2} \mathrm{O}_{2}+$ anta-874. (e and f) Caspase-8 target protector can inhibit caspase-8 reduction and necrosis-induced by $\mathrm{H}_{2} \mathrm{O}_{2}$. Cardiomyocytes were transfected with the target protector (caspase-8-TP ${ }^{\text {miR-874 }}$ ) or the control (caspase-8-TP(ontrol), and then exposed to $\mathrm{H}_{2} \mathrm{O}_{2}$. Caspase-8 levels (e) and $\mathrm{PI}$ exclusion (f) were analyzed, ${ }^{*} \mathrm{P}<0.05$ versus $\mathrm{H}_{2} \mathrm{O}_{2}$ alone

(Supplementary Figure 3C). Taken together, it appears that Foxo3a is able to inhibit necrosis through miR-874 and caspase-8 in the heart.

\section{Discussion}

Necrosis is one of the main form of cell death in heart diseases. Cardiomyocyte death is an important reason for HF, which is one of the leading causes of hospitalization and death worldwide. It is essential to elucidate molecular mechanisms, discover impactful therapeutic targets and suppress myocardial necrosis and the consequent HF. Our present work demonstrated that knockdown of miR-874 attenuated

necrosis in $\mathrm{H}_{2} \mathrm{O}_{2}$-treated cardiomyocytes and $\mathrm{Ml}$ in the animal model. In searching for the downstream targets of miR-874, we found that caspase- 8 was negatively regulated by miR874. MiR-874 affected myocardial necrosis through targeting caspase-8. Moreover, we identified that Foxo3a inhibited myocardial necrosis through transcriptionally targeting miR874. Our results reveal a novel mechanism regulating myocardial necrosis.

Necrosis, in contrast to apoptosis, has been viewed as a form of accidental cell death brought about by injury to the cell by pathogens or toxins. Although several studies have suggested that certain forms of necrosis are programmed, the great breakthrough in the study of programmed necrosis came from the discovery RIPK $1,{ }^{29}$ and RIPK $3,{ }^{30,31}$ the enzymatic activity of which are important in the execution of necrosis. Necrosis is one of the main forms of cell death and its role has been studied in the heart diseases. Recent works had been shown to blockade of necrosis was effective in slowing or reducing cell injury in models of cardiac infarction. Despite its biological importance, the molecular components regulating programmed necrosis in heart are not well defined. Our present work reveals a novel myocardial necrotic regulating pathway, which is composed of Foxo3a, miR-874 and caspase-8. Our results provide new insights for understanding the pathogenesis of myocardial necrosis.

miRNAs are $\sim 22$-nucleotides long and act as negative regulators of gene expression by inhibiting mRNA translation or promoting mRNA degradation. Increasing evidences showed that miRNA has an important role in various biological processes. Despite the biological importance of miRNAs, it is not yet clear whether miRNAs are involved in the regulation of necrosis. In this study, we focused on the functional significance of miR-874, which was the most upregulated miRNA in $\mathrm{H}_{2} \mathrm{O}_{2}$-induced cardiomyocyte necrosis. MiR-874 resides in intron 10 of the gene encoding kelch-like 3 and is related to hypertension. ${ }^{32}$ The present work for the first time demonstrated that miRNA (miR-874) is a prerequisite for $\mathrm{H}_{2} \mathrm{O}_{2}$ to initiate necrosis. Knockdown of miR-874 by antagomir significantly attenuated necrosis in the cellular model and reduced the $\mathrm{Ml}$ size in the animal model upon I/R. We had identified that caspase-8 acted as the downstream target of miR-874. MiR-874 can promote myocardial necrosis through suppressing caspase-8. Our results provide a new clue for the understanding of miRNAs-controlled cellular events, and suggested that miR-874 could be a potential diagnostic markers and therapeutic targets for cardiovascular disease.

Cell death includes two different mechanisms: apoptosis and necrosis. Apoptosis is dependent on caspase activation, whereas the caspase-independent necrotic signaling pathway remains largely uncharacterized. Caspase- 8 has two opposing biological functions, it promotes cell death by triggering the extrinsic pathway of apoptosis, it also has a function in regulating intestinal homeostasis and protecting intestinal epithelial cells from TNF- $\alpha$-induced necrotic cell death. ${ }^{25}$ In murine SVEC cells, knockdown of caspase-8 promotes TNF-induced cell death. In L929 cells, treatment with caspase inhibitor alone has been shown to cause RIPK3-dependent death. ${ }^{26}$ Caspase-8 can cleave both RIPK1 and RIPK3, inhibiting their role in caspase-independent cell death. ${ }^{18}$ However, it is not yet clear whether 
a

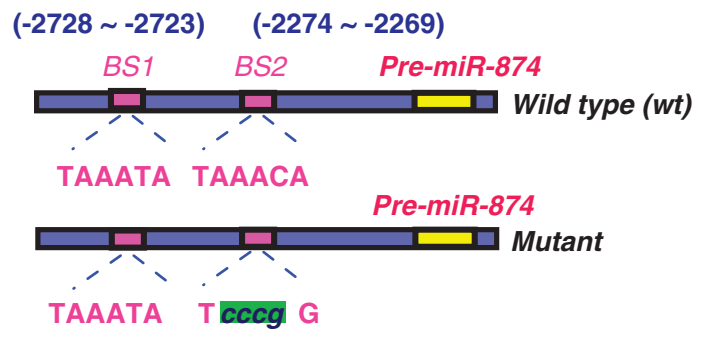

b

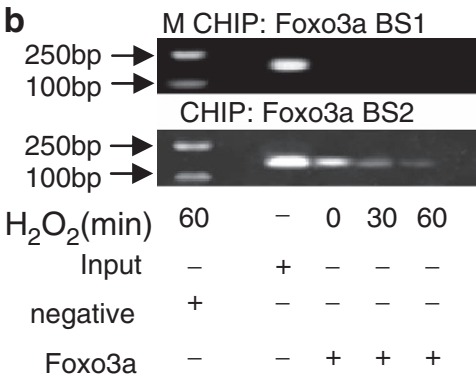

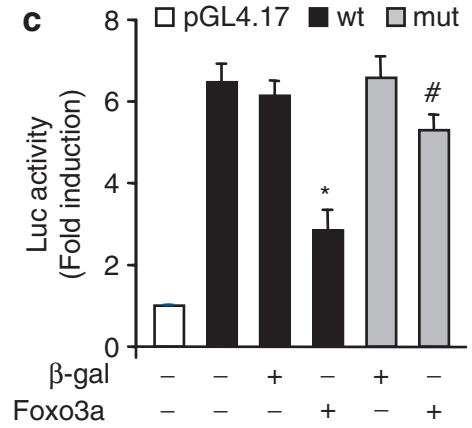

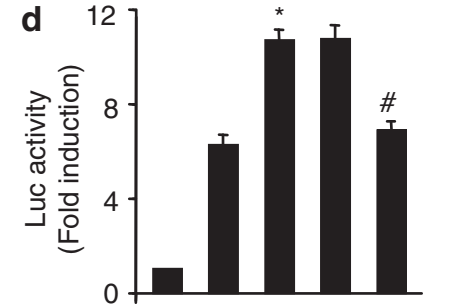

pGL4.17

$$
\begin{array}{rrrrrr}
\text { WT } & - & + & + & + & + \\
\mathrm{H}_{2} \mathrm{O}_{2} & - & - & + & + & + \\
\beta \text {-gal } & - & - & - & + & - \\
\text { Foxo3a } & - & - & - & - & +
\end{array}
$$

e
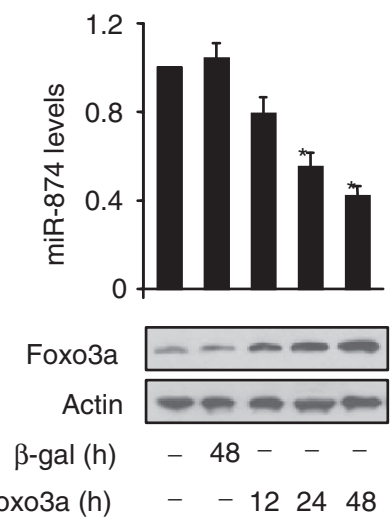

f

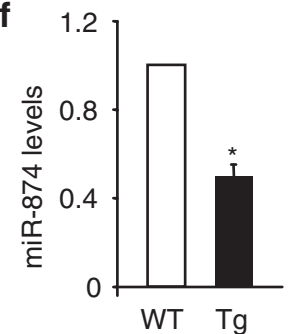

Foxo3a

Actin

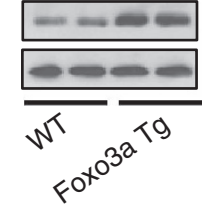

g
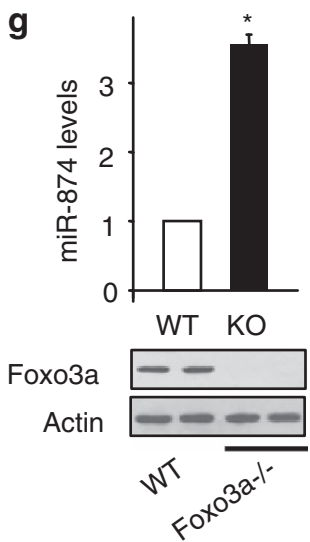

Figure 5 miR-874 is a transcriptional target of Foxo3a. (a) Mouse miR-874 promoter region contains two potential Fox03a-binding site. (b) ChIP analysis of Foxo3a binding to the promoter of miR-874. (c) Fox03a suppressed miR-874 promoter activity. Cardiomyocytes were treated with the adenoviral $\beta$-gal or Foxo3a, the constructs of the empty vector (pGL-4.17), the wild-type promoter (WT) or the promoter with mutations in the binding site (mutant), respectively, ${ }^{*} P<0.05$ versus WT alone; ${ }^{\#} P<0.05$ versus WT + Foxo3a. (d) Foxo3a attenuates the increase of miR-874 promoter activity induced by $\mathrm{H}_{2} \mathrm{O}_{2}$. Cardiomyocytes were treated with the adenoviral $\beta$-gal or Fox03a, the constructs of the empty vector (pGL-4.17), the wild-type promoter (WT), then were treated with $\mathrm{H}_{2} \mathrm{O}_{2},{ }^{*} P<0.05$ versus WT; ${ }^{\#} P<0.05$ versus WT $+\mathrm{H}_{2} \mathrm{O}_{2}$. (e) Fox03a inhibits miR-874 expression. Cardiomyocytes were infected with adenoviral $\beta$-gal or Foxo3a. miR-874 levels were analyzed by RT-PCR, ${ }^{*} P<0.05$ versus control. (f) miR-874 levels in Fox03a transgenic mice. qRT-PCR and immunoblot were performed with Foxo3a transgenic mice (Foxo3a Tg) or the wild-type mice (WT), $n=6,{ }^{*} P<0.05$ versus WT. (g) miR-484 levels in Fox03a-deficient mice. Foxo3a knockout mice (KO), wild-type littermates (WT), $n=5,{ }^{\star} P<0.05$ versus WT

caspase- 8 can regulate oxidative stress-induced necrosis in cardiomyocyte, and the signaling pathway of its in the necrotic machinery remains to be elucidated. Our present work demonstrated that as a target of miR-874, caspase-8 can prevent necrosis in cardiomyocytes. Our results provide novel molecular pathway regulating programmed necrosis in heart.

Forkhead transcription factor Foxo3a participates in regulating diverse cellular functions such as cell cycle arrest, oxidative scavenging, differentiation, metabolism, proliferation, hypertrophy, apoptosis and survival, However, It is currently unknown whether Foxo3a can also regulate necrosis. Our results demonstrated that Foxo3a was able to inhibit necrosis in cellular and animal models and it exerts function by transcriptionally targeting miR-874. Our results for the first time reveal a novel function of Foxo3a-participating in regulating myocardial necrosis.

In summary, our present work identified that miR-874 was able to regulate necrosis in the cellular and animal models. Caspase- 8 is a target of miR-874 in the necrotic pathway. Our results further revealed that Foxo3a was able to inhibit necrosis by transcriptionally targeting miR-874. Modulation of miR-874 levels may provide an intriguing approach for tackling myocardial necrosis. Accordingly, it can be speculated that the identification of miRNAs that regulate necrosis may fill in the gap between unknown aspects of cell biology and the pathogenesis of diseases.

\section{Materials and Methods}

Generation of cardiac-specific Foxo3a transgenic mice. For creating Fox03a transgenic mice, human Fox03a was as we described, ${ }^{33}$ and cloned to the vector p $\alpha \mathrm{MHC}$-clone26 under the control of the $\alpha$-myosin heavy chain promoter. The primers used to generate Foxo3a include, forward primer: 5'-ATGGCAGAGGCACCGGCTTCC-3'; reverse primer: 5'-TCAGCCTGGCACCC AGCTCTGAG-3'. Microinjection was performed following standard protocols.

Generation of Foxo3a knockout mice. Fox03a KO mice were purchased from Mutant Mouse Regional Resource Center, USA. Foxo3a ${ }^{+1-}$ mice were interbred to give $\mathrm{KO}$ mice $\left(\mathrm{FoxO} \mathrm{a}^{-1-}\right.$ ), which were used for further studies. Mice were genotyped by multiplex PCR (primers and conditions are available from Mutant Mouse Regional Resource Center, USA). All experiments were performed on Foxo3a $a^{-1-}$ mice and their wild-type littermates $\left(\right.$ Foxo3a ${ }^{+1+}$ ). The animal experiments were performed according to the protocols approved by the Institute Animal Care Committee.

Cardiomyocyte culture and treatment. Cardiomyocytes were isolated from 1-2 days old mice as we described, ${ }^{33}$ Briefly, after dissection hearts were washed, minced in HEPES-buffered saline solution. Tissues were then dispersed in a series of incubations at $37^{\circ} \mathrm{C}$ in HEPES-buffered saline solution containing $1.2 \mathrm{mg} / \mathrm{ml}$ pancreatin and $0.14 \mathrm{mg} / \mathrm{ml}$ collagenase (Worthington, Lakewood, $\mathrm{NJ}$, USA). After centrifugation cells were resuspended in Dulbecco's modified Eagle medium/F-12 (GIBCO, Grand Island, NY, USA) containing 5\% heat-inactivated 


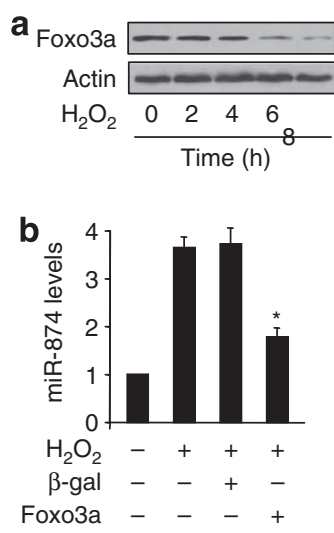

f

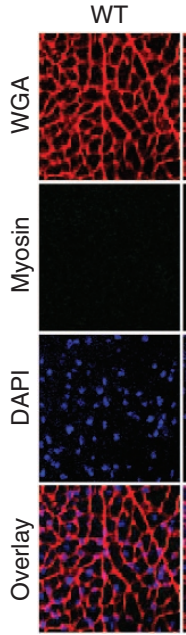

C
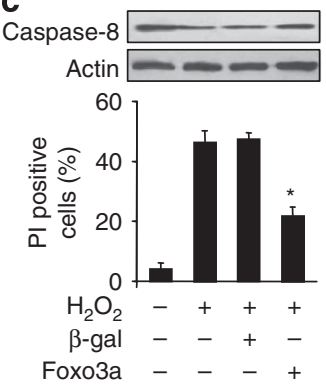

d $\square$ WT $\quad$ FохозаTg

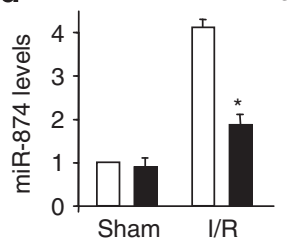

e

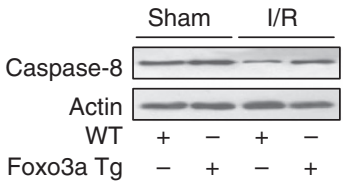

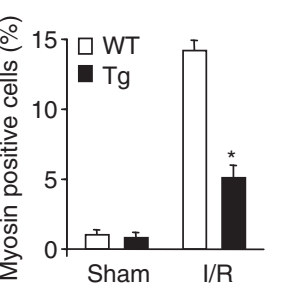

g $\square W T+S h a m \square W T+1 / R$

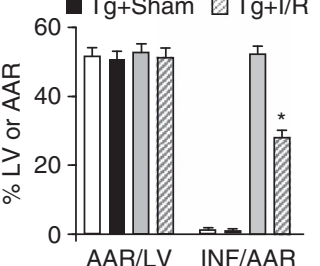

Figure 6 Foxo3a inhibits necrosis through miR-874 and caspase-8. (a) Foxo3a levels are decreased in cardiomyocytes exposed to $\mathrm{H}_{2} \mathrm{O}_{2}$. Cardiomyocytes were exposed to $\mathrm{H}_{2} \mathrm{O}_{2}$. Cells were harvested at the indicated time for the analysis of Foxo3a levels by immunoblot. (b and $\left.\mathbf{c}\right)$ Enforced expression of Foxo3a reduces miR-874 levels and necrotic cell death induced by $\mathrm{H}_{2} \mathrm{O}_{2}$. Cardiomyocytes were infected with adenoviral Foxo3a or $\beta$-gal. Twenty-four hours after infection, cells were treated with $\mathrm{H}_{2} \mathrm{O}_{2}$. miR-874 levels (b), caspase-8 levels (c, upper panel) and PI exclusion were analyzed (c, low panel), ${ }^{*} P<0.05$ versus $\mathrm{H}_{2} \mathrm{O}_{2}$ alone. (d and e) Foxo3a transgenic mice attenuates miR874 levels and increased caspase-8 levels upon I/R. WT and Foxo3a transgenic mice were subjected to I/R as described in methods. miR-874 levels (d) and caspase-8 levels (e) were analyzed. (f and $\mathbf{g}$ ) Foxo3a transgenic mice attenuates myocyte necrosis and MI upon I/R. WT and Foxo3a transgenic mice were subjected to I/R as described in methods. Myocyte necrosis (f) and Ml (g) were analyzed, ${ }^{*} P<0.05$ versus WT $+\mathrm{I} / \mathrm{R}$

horse serum, $0.1 \mathrm{mM}$ ascorbate, insulin-transferring-sodium selenite media supplement (Sigma, St. Louis, MO, USA), $100 \mathrm{U} / \mathrm{ml}$ penicillin, $100 \mu \mathrm{g} / \mathrm{ml}$ streptomycin and $0.1 \mathrm{mM}$ bromodeoxyuridine. The dissociated cells were preplated at $37^{\circ} \mathrm{C}$ for $1 \mathrm{~h}$. The cells were then diluted to $1 \times 10^{6} \mathrm{cell} / \mathrm{s} / \mathrm{ml}$ and plated in $10 \mu \mathrm{g} / \mathrm{ml}$ laminin-coated different culture dishes according to the specific experimental requirements. Cells were treated with $200 \mu \mathrm{M}$ or $500 \mu \mathrm{M} \mathrm{H}_{2} \mathrm{O}_{2}$ except as otherwise indicated elsewhere. For TNF- $\alpha$-stimulated cells, cells were exposed $10 \mathrm{ng} / \mathrm{ml}$ human TNF- $\alpha$ at indicated time.

Cell death assays. Apoptosis was measured with the Vybrant FAM caspase3 and -7 assay kit (Invitrogen, Grand Island, NY, USA) according to manufacturers protocol. The detection procedures were in accordance with the kit instructions. Necrotic cell death was assessed by propidium iodide (PI) exclusion. Flow cytometry experiments were performed on a FACS Calibur (Becton Dickinson, Franklin Lakes, NJ, USA).

Adenoviral constructions and infection. Mouse caspase-8 CDNA was amplified by RT-PCR from total RNA of mouse heart and then cloned into pcDNA3.1, The adenoviruses harboring Caspase-8 were constructed using the Adeno-X expression system (Clontech, Otsu, Japan). The adenovirus harboring Caspase- $-8^{\mathrm{C} 360 \mathrm{~S}}$, which contains a cysteine to serine mutation at the catalytically active site, were generated using QuikChange II XL Site-Directed Mutagenesis Kit
(Stratagene, La Jolla, CA, USA) and were also constructed using the Adeno-X expression system (Clontech). Caspase-8 3 'UTR mutants were generated using QuikChange II XL Site-Directed Mutagenesis Kit (Stratagene). Adenoviral Fox03a was as we described, ${ }^{33}$ The adenovirus containing $\beta$-galactosidase ( $\beta$-gal) is as we described elsewhere, ${ }^{34}$ To construct adenovirus encoding miR-874, mouse genomic sequence harboring the pre-miR-874 was amplified using the following primer set: 5'-GCTTTCTGGTTGACACATGCT-3'; 5'-TAAACGTGTGTGGATCGAGAC- $3^{\prime}$. The constructs were sequence verified and cloned into the adenovirus system. The adenoviral constructs were prepared using the Adeno-X Expression System (Clontech) according to the manufacturer's instructions.

Constructions of adenoviruses harboring mouse Caspase-8 RNAi, RIPK1-siRNA and RIPK3-siRNA. The mouse Caspase-8 RNAi target sequence is $5^{\prime}$-CCTCGGGGATACTGTCTGA-3'. A nonrelated, scrambled RNAi without any other match in the mouse genomic sequence was used as a control (5'-GTCAGTCTGCAGTCGTAGC- $\left.3^{\prime}\right)$. The mouse RIPK1 target sequence is $5^{\prime}$-CAACCGCGCTGAGTACAAT- $3^{\prime}$ and the scramble sequence is $5^{\prime}$-CACA GTAGCTCAGACTACG- $3^{\prime}$. The mouse RIPK3 target sequence is $5^{\prime}$-ACACGG CACTCCTTGGTAT- $3^{\prime}$ and the scramble sequence is $5^{\prime}$-CTGACTCAGTAC TAGCTCG- ${ }^{\prime}$. The adenoviruses harboring these RNAi constructs were generated using the pSilencer adeno 1.0-CMV System (Ambion, Grand Island, NY, USA) according to the Kit's instructions. Adenoviruses were amplified in HEK293 cells. 
Adenoviral infection of cardiomyocytes was performed as we described previously. $^{35}$

Immunoblot. Immunoblot was performed as we described, ${ }^{33}$ In brief, cells were lysed for $1 \mathrm{~h}$ at $4^{\circ} \mathrm{C}$ in a lysis buffer (20 mM Tris (pH 7.5), $2 \mathrm{mM}$ EDTA, $3 \mathrm{mM}$ EGTA, $2 \mathrm{mM}$ DTT, $250 \mathrm{mM}$ sucrose, $0.1 \mathrm{mM}$ PMSF, 1\% Triton X-100 and a protease inhibitor cocktail). Samples were subjected to $12 \%$ SDS-PAGE and transferred to nitrocellulose membranes. Equal-protein loading was controlled by Ponceau red staining of membranes. Blots were probed using the primary antibodies. The antibodies to caspase- 8 was from Abcam. The antibody to Foxo3a was from Cell Signaling (Danvers, MA, USA). The antibody to CYLD N terminus was from Invitrogen. The horseradish peroxidase-conjugated secondary antibodies were purchased from Santa Cruz Biotechnology (Santa Cruz, CA, USA).

Transfection of antagomir. miR-874 antagomir and the antagomir negative control (antagomir-NC) were purchased from GenePharma Co. Ltd (Shanghai, China). The antagomir sequence is $5^{\prime}$-UCGGUCCCUCGGGCCAGGG CAG- $3^{\prime}$. All the bases were $2^{\prime}$-OMe modified, and the $3^{\prime}$-end was conjugated to cholesterol. Chemically modified oligonucleotides $5^{\prime}$-CAGUACUUUUGUGUAGUA CAA- $3^{\prime}$ were used as a negative control (antagomir-NC). Cells were transfected with the antagomir or antagomir-NC at $50 \mathrm{nM}$. The transfection was performed using Lipofectamine 2000 (Invitrogen) according to the manufacturer's instruction.

Target protector preparation and transfection. Target protector was designed and named as others and we described, ${ }^{27}$ In brief, Caspase-8-TP ${ }^{\text {miR-874 }}$ sequence is $5^{\prime}$-TGTATTGCCCAACTATTCTTGGGAG-3'. Caspase-8-TP ${ }^{\text {control }}$ sequence is $5^{\prime}$-TGACAAATGAGACTCTCTCCTCTCC- $3^{\prime}$. They were synthesized by Gene Tools (Philomath, OR, USA), and transfected into the cells using the Endo-Porter kit (Gene Tools) according to the kit's instructions.

Preparations of the luciferase construct of Caspase-8 $3^{\prime}$ UTR and luciferase activity assay. Caspase- $83^{\prime}$ UTR was amplified by PCR. The forward primer was 5'-GTGCTCTCCACAGTTCACATG-3'; the reverse primer was $5^{\prime}$-AGGTCCCTGCTCCCGTCATTC- $3^{\prime}$. To produce mutated $3^{\prime} U T R$, the mutations were generated using QuikChange II XL Site-Directed Mutagenesis Kit (Stratagene). The constructs were sequence verified. Wild-type and mutated $3^{\prime}$ UTRs were subcloned into the pGL3 vector (Promega, Madison, WI, USA) immediately downstream of the stop codon of the luciferase gene.

Luciferase activity assay was performed using the Dual-Luciferase Reporter Assay System (Promega) according to the manufacturer's instructions. Cells were co-transfected with the plasmid constructs of $150 \mathrm{ng} /$ well of pGL3-Caspase-8$3^{\prime}$ UTR or pGL3-Caspase-8-3'UTR-mut using Lipofectamine 2000 (Invitrogen), then were infected with adenovirus miR-874 or $\beta$-gal at a moi of 80 . At $48 \mathrm{~h}$ after infection, luciferase activity was measured.

Quantitative reverse transcription-polymerase chain reaction. Stem-loop qRT-PCR for mature miR-874 was performed as described, ${ }^{36}$ on an Applied Biosystems ABI Prism 7000 sequence detection system. Total RNA was extracted using Trizol reagent. After DNAse I (Takara, Japan) treatment, RNA was reverse transcribed with reverse transcriptase (ReverTra Ace, Toyobo, Osaka, Japan). The results of qRT-PCR were normalized to that of U6. The sequences of U6 primers were forward: 5'-GCTTCGGCAGCACATATACTAA-3'; reverse: 5'-AACGCTTCACGAATTTGCGT-3'.

Constructions of mouse miR-874 promoter and its mutant. We downloaded 5-kb region upstream sequences of mouse miR-874, and found two potential Foxo3a-binding sites in $(-2723 \sim-2728)$ and $(-2269 \sim-2274)$. A $1722 \mathrm{bp}$ fragment contained the two-binding sites was cloned into the vector pGL4.17 (Promega). The fragment was amplified from mouse genome using PCR. The forward primer was $5^{\prime}$-GTGCTGACTGACTGCTCACCT-3'; the reverse primer was $5^{\prime}$-GGAAGTCTGCCTCTCTGTTTC- ${ }^{\prime}$. The introduction of mutations in the putative Fox03a-binding site was performed with the QuikChange II XL Site-Directed Mutagenesis Kit (Stratagene) using the wild-type vector as a template. The construct was sequenced to check that only the desired mutations had been introduced.

Chromatin immunoprecipitation assay. ChIP assay was performed as we described, ${ }^{27}$ In brief, cells were washed with PBS and incubated for $10 \mathrm{~min}$ with $1 \%$ formaldehyde at room temperature. The crosslinking was quenched with $0.1 \mathrm{M}$ glycine for $5 \mathrm{~min}$. Cells were washed twice with PBS and lysed for $1 \mathrm{~h}$ at
$4{ }^{\circ} \mathrm{C}$ in a lysis buffer. The cell lysates were sonicated into chromatin fragments with an average length of 500 to $800 \mathrm{bp}$ as assessed by agarose gel electrophoresis. The samples were precleared with Protein-A agarose (Roche, Hamburg, Germany) for $1 \mathrm{~h}$ at $4{ }^{\circ} \mathrm{C}$ on a rocking platform, and $5 \mu$ g-specific antibodies were added and rocked for overnight at $4{ }^{\circ} \mathrm{C}$. Immunoprecipitates were captured with $10 \%$ (vol/vol) Protein-A agarose for $4 \mathrm{~h}$. Before use, Protein-A agarose was blocked twice at $4{ }^{\circ} \mathrm{C}$ with salmon sperm DNA $(2 \mu \mathrm{g} / \mathrm{ml})$ overnight. DNA fragments were purified with a QIAquick Spin Kit (Qiagen, Hamburg, Germany). The purified DNA was used as a template and amplified with the following primer sets: For the analysis of Fox03a binding to the promoter region of miR-874, the oligonucleotides were as follows: BS1 forward primer: 5'-GCACCCTGCTTTATAGAATGT-3'; reverse primer: $5^{\prime}$-AGTGCTGGGCAACTG TTGGTT-3'. BS2 forward primer: 5'-TTGTCACCAGAAGCGTCCACA-3'; reverse primer: $5^{\prime}$-TAGGTGAGTCCCTGAACCCTA-3'

Transmission electron microscopy. Conventional electron microscopy was performed as described previously. ${ }^{37}$ In brief, cells were fixed with $2.5 \%$ glutaraldehyde and then postfixed with $1 \%$ osmium tetraoxide, dehydrated in a graded series of ethanol concentrations, and embedded in Embed812 resin. The ultrathin sections were mounted on copper grids and then double-stained with uranyl acetate and lead citrate. The samples were examined and photographed with a FEI Tecnai spirit transmission electron microscope.

Microarray analysis. Total RNA was extracted from cardiomyocytes by using Trizol reagent. For the miRNA microarray experiments, low-molecular-weight RNA was isolated with the described method, ${ }^{38}$ and then used for miRNA expression analysis with miRNA microarray (CapitalBio Corp., Beijing, China).

miR-874 antagomir delivery, l/R, preparations of area at risk and histology. Male adult C57BL/6 mice (8-weeks-old) were obtained from Institute of Laboratory Animal Science of Chinese Academy of Medical Sciences (Beijing, China). All experiments were performed according to the protocols approved by the Institute Animal Care Committee. The mice received on three consecutive days, intravenous injections of miR-874 antagomir, or its control at a dose of $30 \mathrm{mg} / \mathrm{kg}$ body weight in a small volume $(0.2 \mathrm{ml})$ per injection. Foxo3a transgenic mice, Foxo3a KO mice and WT mice were subjected to 60 min ischemia, then $24 \mathrm{~h}$ or 1 week reperfusion. Sham-operated group experienced the same procedure except the snare was left untied. Evans blue dye was treated as described, ${ }^{39}$ The areas of infarction (INF), area at risk (AAR), and nonischemic left ventricle (LV) were assessed with computer-assisted planimetry (NIH Image 1.57) by an observer blinded to the sample identity. The ratio of AAR/LV, INF/AAR and INF/LV were calculated as described. ${ }^{39}$

Echocardiographic assessment. Transthoracic echocardiographic analysis was performed on mice after the sham or I/R surgery as we described. ${ }^{27}$ Echocardiographic parameters such as systolic left ventricular internal diameters (LVIDs) and diastolic left ventricular internal diameters (LVIDd) were measured. Fractional shortening (FS) of left ventricular diameter was calculated as $[(L V I D d-L V I D s) / L V I D d] \times 100$. After in vivo evaluation of cardiac function the mice were euthanized and the hearts were harvested, weighted and used for histological examination.

Statistical analysis. Data are expressed as the mean \pm S.E.M. of at least three independent experiments. We used a one-way analysis of variance for multiple comparisons. A value of $P<0.05$ was considered significant.

\section{Conflict of Interest}

The authors declare no conflict of interest.

Acknowledgements. This work was supported by National Natural Science Foundation of China $(30871243,31010103911,81270160,81000034)$ and $\mathrm{NIH}$ (1R01HL102202).

1. Lee $\mathrm{Y}$, Ahn C, Han J, Choi H, Kim J, Yim J et al. The nuclear mase iii drosha initiates microrna processing. Nature 2003; 425: 415-419.

2. Ohtani K, Dimmeler S. Control of cardiovascular differentiation by micrornas. Basic Res Cardiol 2011; 106: 5-11. 
3. Qian L, Van Laake LW, Huang Y, Liu S, Wendland MF, Srivastava D. Mir-24 inhibits apoptosis and represses bim in mouse cardiomyocytes. J Exper Med 2011; 208: 549-560.

4. Wang X, Zhang X, Ren XP, Chen J, Liu H, Yang J et al. Microrna-494 targeting both proapoptotic and antiapoptotic proteins protects against ischemia/reperfusion-induced cardiac injury. Circulation 2010; 122: 1308-1318.

5. Sayed D, He M, Hong C, Gao S, Rane S, Yang Z et al. Microrna-21 is a downstream effector of akt that mediates its antiapoptotic effects via suppression of fas ligand. J Biol Chem 2010; 285: 20281-20290.

6. Li P. Micrornas in cardiac apoptosis. J Cardiovasc Transl Res 2010; 3: 219-224.

7. Thum T, Galuppo P, Wolf C, Fiedler J, Kneitz S, van Laake LW et al. Micrornas in the human heart: a clue to fetal gene reprogramming in heart failure. Circulation 2007; 116: 258-267.

8. Chien KR. Molecular medicine: Micrornas and the tell-tale heart. Nature 2007; 447: 389-390.

9. Basson M. Micrornas loom large in the heart. Nat Med 2007; 13: 541.

10. Kroemer G, El-Deiry WS, Golstein P, Peter ME, Vaux D, Vandenabeele $P$ et al. Classification of cell death: recommendations of the nomenclature committee on cell death. Cell Death Differ 2005; 12(Suppl 2): 1463-1467.

11. Degterev A, Huang Z, Boyce M, Li Y, Jagtap P, Mizushima N et al. Chemical inhibitor of nonapoptotic cell death with therapeutic potential for ischemic brain injury. Nat Chem Biol 2005; 1: 112-119.

12. Cauwels A, Janssen B, Waeytens A, Cuvelier $C$, Brouckaert P. Caspase inhibition causes hyperacute tumor necrosis factor-induced shock via oxidative stress and phospholipase a2. Nat Immunol 2003; 4: 387-393.

13. Mareninova OA, Sung KF, Hong P, Lugea A, Pandol SJ, Gukovsky I et al. Cell death in pancreatitis: caspases protect from necrotizing pancreatitis. J Biol Chem 2006; 281: 3370-3381.

14. Konstantinidis K, Whelan RS, Kitsis RN. Mechanisms of cell death in heart disease. Arterioscler Thromb Vasc Biol 2012; 32: 1552-1562.

15. Guerra S, Leri A, Wang X, Finato N, Di Loreto C, Beltrami CA et al. Myocyte death in the failing human heart is gender dependent. Circ Res 1999; 85: 856-866.

16. Smith CC, Davidson SM, Lim SY, Simpkin JC, Hothersall JS, Yellon DM. Necrostatin: A potentially novel cardioprotective agent? Cardiovasc Drugs Ther 2007; 21: 227-233.

17. Feng S, Yang Y, Mei Y, Ma L, Zhu DE, Hoti N et al. Cleavage of rip3 inactivates its caspase-independent apoptosis pathway by removal of kinase domain. Cell Signal 2007; 19: 2056-2067.

18. Lin Y, Devin A, Rodriguez Y, Liu ZG. Cleavage of the death domain kinase rip by caspase-8 prompts tnf-induced apoptosis. Genes \& Development 1999; 13: 2514-2526.

19. Anderson MJ, Viars CS, Czekay S, Cavenee WK, Arden KC. Cloning and characterization of three human forkhead genes that comprise an fkhr-like gene subfamily. Genomics 1998; 47: 187-199.

20. Accili D, Arden KC. Foxos at the crossroads of cellular metabolism, differentiation, and transformation. Cell 2004; 117: 421-426.

21. Skurk C, Izumiya $Y$, Maatz H, Razeghi P, Shiojima I, Sandri M et al. The foxo3a transcription factor regulates cardiac myocyte size downstream of akt signaling. $J$ Biol Chem 2005; 280: 20814-20823.

22. Gardner AM, Xu FH, Fady C, Jacoby FJ, Duffey DC, Tu Y et al. Apoptotic vs. nonapoptotic cytotoxicity induced by hydrogen peroxide. Free Radic Biol Med 1997; 22: 73-83.

23. Takeda M, Shirato I, Kobayashi M, Endou H. Hydrogen peroxide induces necrosis, apoptosis, oncosis and apoptotic oncosis of mouse terminal proximal straight tubule cells. Nephron 1999; 81: 234-238.
24. Troyano A, Sancho P, Fernandez C, de Blas E, Bernardi P, Aller P. The selection between apoptosis and necrosis is differentially regulated in hydrogen peroxide-treated and glutathione-depleted human promonocytic cells. Cell Death Differ 2003; 10: 889-898.

25. Gunther C, Martini E, Wittkopf N, Amann K, Weigmann B, Neumann H et al. Caspase-8 regulates tnf-alpha-induced epithelial necroptosis and terminal ileitis. Nature 2011; 477: $335-339$.

26. Oberst A, Dillon CP, Weinlich R, McCormick LL, Fitzgerald P, Pop C et al. Catalytic activity of the caspase-8-flip(I) complex inhibits ripk3-dependent necrosis. Nature 2011; 471: 363-367.

27. Lin Z, Murtaza I, Wang K, Jiao J, Gao J, Li PF. Mir-23a functions downstream of nfatc3 to regulate cardiac hypertrophy. Proc Natl Acad Sci USA 2009; 106: 12103-12108.

28. O'Donnell MA, Perez-Jimenez E, Oberst A, Ng A, Massoumi R, Xavier R et al. Caspase 8 inhibits programmed necrosis by processing cyld. Nat Cell Biol 2011; 13: 1437-1442.

29. Holler N, Zaru R, Micheau O, Thome M, Attinger A, Valitutti S et al. Fas triggers an alternative, caspase-8-independent cell death pathway using the kinase rip as effector molecule. Nat Immunol 2000; 1: 489-495.

30. He S, Wang L, Miao L, Wang T, Du F, Zhao L et al. Receptor interacting protein kinase-3 determines cellular necrotic response to tnf-alpha. Cell 2009; 137: 1100-1111.

31. Cho YS, Challa S, Moquin D, Genga R, Ray TD, Guildford M et al. Phosphorylation-driven assembly of the rip1-rip3 complex regulates programmed necrosis and virus-induced inflammation. Cell 2009; 137: 1112-1123.

32. Boyden LM, Choi M, Choate KA, Nelson-Williams CJ, Farhi A, Toka HR et al. Mutations in kelch-like 3 and cullin 3 cause hypertension and electrolyte abnormalities. Nature 2012; 482: 98-102.

33. Tan WQ, Wang K, Lv DY, Li PF. Foxo3a inhibits cardiomyocyte hypertrophy through transactivating catalase. J Biol Chem 2008; 283: 29730-29739.

34. Li PF, Dietz R, von Harsdorf R. P53 regulates mitochondrial membrane potential through reactive oxygen species and induces cytochrome c-independent apoptosis blocked by bcl2. The EMBO J 1999; 18: 6027-6036.

35. Murtaza I, Wang HX, Feng X, Alenina N, Bader M, Prabhakar BS et al. Down-regulation of catalase and oxidative modification of protein kinase ck2 lead to the failure of apoptosis repressor with caspase recruitment domain to inhibit cardiomyocyte hypertrophy. J Biol Chem 2008; 283: 5996-6004.

36. Chen C, Ridzon DA, Broomer AJ, Zhou Z, Lee DH, Nguyen JT et al. Real-time quantification of micrornas by stem-loop rt-pcr. Nucleic Acids Res 2005; 33: e179.

37. Moreau K, Ravikumar B, Renna M, Puri C, Rubinsztein DC. Autophagosome precursor maturation requires homotypic fusion. Cell 2011; 146: 303-317.

38. Thomson JM, Parker J, Perou CM, Hammond SM. A custom microarray platform for analysis of microrna gene expression. Nat Methods 2004; 1: 47-53.

39. Wang JX, Jiao JQ, Li Q, Long B, Wang K, Liu JP et al. Mir-499 regulates mitochondrial dynamics by targeting calcineurin and dynamin-related protein-1. Nat Med 2011; 17: $71-78$.

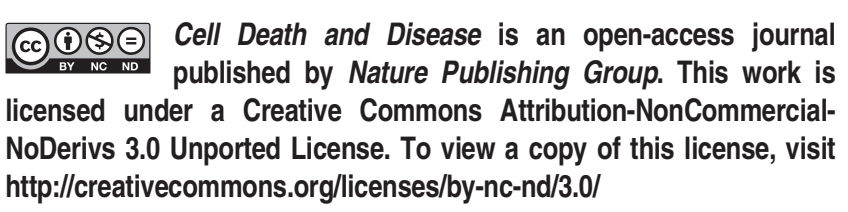

